\section{Hyperinsulinaemia and blood pressure in patients with insulinoma}

\author{
Noriko Fujita, Tsuneharu Baba, \\ Tsukiko Tomiyama, Tatsuhiko Kodama, \\ Norio Kako
}

Third Department of
Internal Medicine and First
Department of Surgery,
Hirosaki University School
of Medicine, Hirosaki,
Japan
Noriko Fujita, postgraduate
student
Tsuneharu Baba, senior
lecturer
Tsukiko Tomiyama, senior
researcher
Tatsuhiko Kodama,
postgraduate student
Norio Kako, senior lecturer in
surgery

Correspondence to:

Dr T Baba, Division of Clinical Pharmacology, Clinical Research Institute, National Medical Centre, 1-21-2 Toyama,

Shinjuku-ku, Tokyo 162, Japan.

BMF 1992;304:1157 chronic hyperinsulinaemia on blood pressure.

\section{Patients, methods, and results}

A possible link between hyperinsulinaemia or insulin resistance and hypertension is currently debated. Recent evidence suggests that patients with essential hypertension are insulin resistant ${ }^{12}$ and that hyperinsulinaemia is associated with raised blood pressure in subjects with normal glucose tolerance. ${ }^{3}$ Insulin enhances sodium reabsorption from the renal tubules and stimulates the activity of the sympathetic nervous system. ${ }^{5}$ Nevertheless, it is yet unknown whether hyperinsulinaemia itself is causally related to increased blood pressure or is merely the consequence of insulin resistance in hypertensive patients. This study was designed to evaluate the relation between serum insulin concentration and blood pressure in non-obese patients with insulinoma in order to study the effect of

We evaluated data obtained from eight Japanese patients with insulinoma (six women and two men, mean (range) age 41 (24-56), mean (range) body mass index $\left.22 \cdot 5(21-25) \mathrm{kg} / \mathrm{m}^{2}\right)$ admitted to Hirosaki University Hospital during 1973-89. The mean duration of the disease was assumed to be $34 \cdot 8$ (range 2-62) months, estimated from the time of appearance of the first hypoglycaemic symptom(s). The diagnosis of insulinoma was confirmed by histological examination of the resected insuloma in all patients. The renal, hepatic, and cardiac functions of the eight patients were all within normal ranges. Two patients had a familial history of hypertension and the remaining six did not. Ninety three non-obese subjects (45 women and 48 men, mean (range) age $48(20-65)$, mean (range) body mass index $\left.23 \cdot 2(18-26) \mathrm{kg} / \mathrm{m}^{2}\right)$ with normal glucose tolerance, according to the World Health Organisation criteria, served as controls.

We compared, firstly, the blood pressure of the patients with insulinoma with that of the controls and, secondly, blood pressure, and serum insulin and fasting plasma glucose concentrations before and after resection of the insulinoma. Blood pressure was measured in the supine position at 800 am and fasting

Geometric mean of serum insulin and blood pressure concentrations (95\% confidence interval) in eight patients with insulinoma before and after operation and controls

\begin{tabular}{|c|c|c|c|}
\hline & \multicolumn{2}{|c|}{ Patients with insulinoma } & \multirow[b]{2}{*}{ Controls } \\
\hline & Before operation & After operation & \\
\hline $\begin{array}{l}\text { Fasting serum insulin }(\mathrm{pmol} / \mathrm{l}) \\
\text { Fasting plasma glucose }(\mathrm{mmol} / \mathrm{l}) \\
\text { Systolic blood pressure }(\mathrm{mm} \mathrm{Hg}) \\
\text { Diastolic blood pressure }(\mathrm{mm} \mathrm{Hg}) \\
\text { Body mass index }\left(\mathrm{kg} / \mathrm{m}^{2}\right)\end{array}$ & $\begin{array}{l}159(121 \text { to } 196)^{\star} \\
2 \cdot 6(2 \cdot 1 \text { to } 3 \cdot 1)^{\star} \\
117(106 \text { to } 127) \\
69(62 \text { to } 75) \\
22 \cdot 5(21 \cdot 0 \text { to } 23 \cdot 9)\end{array}$ & $\begin{array}{l}66(39 \text { to } 92) \\
5 \cdot 1(4 \cdot 8 \text { to } 5 \cdot 4) \\
130(121 \text { to } 138) \\
78(70 \text { to } 85) \\
21 \cdot 4(19 \cdot 9 \text { to } 22 \cdot 8)\end{array}$ & $\begin{array}{l}65(58 \text { to } 69) \\
5 \cdot 4(5 \cdot 2 \text { to } 5 \cdot 5) \\
124(121 \text { to } 126) \\
77(74 \text { to } 79) \\
23 \cdot 2(22 \cdot 5 \text { to } 23 \cdot 7)\end{array}$ \\
\hline
\end{tabular}

${ }^{\star} \mathrm{p}<0 \cdot 05$ Compared with controls and patients after operation. serum insulin and plasma glucose concentrations at least three times in each patient both before and 1-2 months after the operation. Differences in the values were tested by Wilcoxon's rank sum test or Wilcoxon's signed rank test, when appropriate. Correlation between the serum insulin concentration and mean blood pressure was evaluated by Spearman's rank correlation coefficient. A p value less than $5 \%$ was considered significant.

Neither the systolic nor diastolic blood pressure before operation in the patients with insuloma was higher than in the controls (table). The resection of the insulinoma caused a significant fall in serum insulin concentration and an increase in plasma glucose concentration but did not lower blood pressure. There was no significant correlation $\left(r_{s}=0.030\right)$ between the serum insulin concentration and mean blood pressure in the patients.

\section{Comment}

Insulin is considered to have a role as a pressor factor. ${ }^{45}$ Nevertheless, blood pressure in our patients with insulinoma, who were assumed to be sensitive to insulin, was not higher than in the controls and was not reduced after resection of the insulinoma. These results suggest that hyperinsulinaemia in patients with insulinoma is not associated with increased blood pressure. The precise reason(s) for the lack of association between serum insulin concentration and blood pressure in our patients is unclear. The period of hyperinsulinaemia in the patients with insuloma might have been too short for a change in blood pressure to develop compared with that experienced by hypertensive patients. Although the results obtained from this small number of patients need to be interpreted with caution, the observations imply that a few years of hyperinsulinaemia itself may not increase blood pressure in non-obese subjects with normal kidney function, and this deserves further investigation.

1 Modan M, Halkin H, Almog S, Lusky A, Exhko A, Shen M, et al. Hyperinsulinaemia. A link between hypertension obesity and glucose intolerance. F Clin Invest 1985; 75:809-17.

2 Ferrannini E, Buzzigoli G, Bonadonna R, Giorico MA, Oleggnini $M$, Graziadei $\mathrm{L}$, et al. Insulin resistance in essential hypertension. $N$ Engl $\mathcal{F} \mathrm{Med}$ 1987;317:350-7.

3 Zavaroni I, Bnora E, Pagliara M, Dall'Aglio E, Luchetti L, Buonanno G, et al. Risk factors for coronary artery disease in healthy persons with hyperinsulinemia and normal glucose tolerance. $N$ Engl f Med 1989;320:702-6.

4 Skøtt P, Hother-Nielsen O, Bruun NE, Giese J, Nielsen MD, Beck-Nielsen H, et al. Effects of insulin on kidney function and sodium excretion in healthy et al. Effects of insulin on kidney funct

5 Rowe JW, Young JB, Ninaker KL, Stevens AL, Pallotta J. Landsberg L. Effect of insulin and glucose infusions on sympathetic nervous system activity in normal man. Diabetes 1981;30:219-25.

(Accepted 11 November 1991)

\section{Correction}

Respiratory symptoms and atopy in Aberdeen schoolchildren: evidence from two surveys 25 years apart

An authors' error occurred in this paper by Titus K Ninan and George Russell (4 April, pp 873-5). In the abstract, the number of participants in 1989 should read 4003 (not 3942 as published); this number also applies in paragraph 4 of the materials and methods section and in the first paragraph of the results section. The percentage of questionnaires completed (paragraph 4 of methods section) becomes $85 \cdot 0 \%(3403 / 4003)$. 